\title{
Numerical Investigation of Turbulent Natural Convection for a Cavity Having Sinusoidal Protuberances on a Vertical Wall
}

\author{
K. Rahmani ${ }^{1 \dagger}$, A. Bentebbiche ${ }^{1}$ and B. Draoui ${ }^{2}$ \\ ${ }^{I}$ LMA Laboratory, Mechanical Engineering Faculty -University of Sciences and Technology, USTHB, Algiers, Algeria. \\ ${ }^{2}$ Mechanical Engineering Faculty, University of Bechar, Algeria \\ †Corresponding Author Email: kouiderrah1@gmail.com
}

(Received February 21, 2012; accepted September 20, 2012)

\begin{abstract}
This work concerns the study of heat transfer by means of natural convection with fluids circulating in enclosures. This is largely studied both experimentally and numerically due to their wide industrial application in various fields such as nuclear energy, the heating and cooling of buildings, solar collectors, etc. A great deal of relevant research work consists of numerical simulations of natural convection mechanisms with laminar flows in closed cavities. In this context, the present study comes as a contribution in numerical form of investigating the turbulent natural convection in a vertical enclosure which has sinusoidal protuberances on one of its vertical walls. Both the top and bottom of the enclosure are open to allow the fluid flow. The horizontal walls are supposed to be adiabatic.

We are interested in determining the flow for various amplitudes and periods. The influence of geometry on several factors such as: temperature, the local Nusselt number, turbulent kinetic energy $k$ and its dissipation $\varepsilon$ are considered. Based on the Navier-Stokes equations and Boussinesq approximation, the equations were solved by a CFD technique using the Finite Volume Method in the case of enclosures having the form ratio equal to 0.6 ( $\mathrm{A}=0.6$ ). Given the steady conditions of heat flow on the vertical walls and the pressures at the entry and exit of the cavity, the results show that when we gradually increase the amplitudes of the protuberance wall (say $a=0.005 \mathrm{~m}, \mathrm{a}=0.010, \mathrm{a}=0.015, \mathrm{a}=$ 0.02 , and $\mathrm{a}=0.025$ ), the maximal temperature increases with the increase of amplitude. This is due to the rise of the heat transfer surface of the modified wall. Regarding heat transfer parameters, the results show that the number of local Nusselt varies accordingly with the amplitudes. This explains that the modified wall is affected locally by a pure conduction. The results obtained in this study are in agreement with recent works of several authors.
\end{abstract}

Keywords: Natural convection, Turbulence, Modeling, CFD.

\section{NOMENCLATURE}

$\begin{array}{ll}\text { a } & \text { amplitude wave } \\ B & \text { thermal expansion coefficient } \\ \mathrm{Gr} * & \text { modified Grashof number } \\ \mathrm{H} & \text { height of the cavity } \\ \mathrm{h} & \text { height of protuberance } \\ k & \text { turbulent kinetic energy } \\ \mathrm{L} & \text { length of the cavity } \\ \mathrm{N}_{\mathrm{u}} & \text { Nusselt number } \\ \mathrm{N}_{\mathrm{ux}} & \text { local Nusselt number } \\ \mathrm{P} & \text { pressure, } \mathrm{P}_{\mathrm{a}} \\ \mathrm{P}_{\mathrm{r}} & \text { Prandtl number }\end{array}$

\section{INTRODUCTION}

The analysis of heat transfer by natural convection and the circulation of fluids in enclosures were largely studied using experimental and numerical techniques.

Because of their large application in nuclear energy, the heating and cooling of buildings, solar collectors, etc, several works have made numerical studies on laminar

$\begin{array}{ll}\mathrm{q} & \text { heat flux } \\ \mathrm{U}, \mathrm{V} & \text { dimensionless axial and radial velocities } \\ X, Y & \text { dimensionless coordinates } \\ \theta & \text { dimensionless temperature } \\ \theta \mathrm{p} & \text { dimensionless temperature at the wall } \\ \Psi & \text { dimensionless stream function } \\ \tau & \text { dimensionless time } \\ \varepsilon & \text { turbulence dissipation rate } \\ \mu_{t} & \text { dynamic turbulence viscosity } \\ \mu & \text { dynamic viscosity } \\ v & \text { cinematic viscosity }\end{array}$

flows inside closed cavities taking into account the mechanism of natural convection. Larson and Viskanta (1976) have numerically studied the heat transfer in an opaque closed square cavity. In a similar study, Webb and Viskanta (1987) have included a semi-transparent vertical wall (glass leaf) in the cavity. Behnia et al. (1990) have also examined a rectangular cavity with 
Semi-transparent wall. The wall had convection loss in its environment.

The results of Bahnia et al. (1990) indicate that the external convection weakens the circulation of internal flows. Further studies are already classified, namely Ostrich (1988), Catton (1978), Bejan (1995), Khalifaabduljabe (2001), and Vahl Davis et al. (1983).

Esherbiny (1996) has carried out an experimental study on convection heat transfer in an inclined, closed enclosure. Bairi et al. (2007) have realized a study with a high number of Rayleigh in a rectangular enclosure using numerical and experimental techniques.

Aounallah et al. (2007) have performed a numerical study on the turbulent natural convection of air flow in a cavity being limited to two outside heated walls until a high number of Rayleigh $\left(10^{12}\right)$ by which they have analyzed the slope effects. The models of turbulence were soon reviewed by Chowdhury and Ahmadi (1992). The requirements of the models were integrated in a recent study of Yilmaz and Oztop (2006) on turbulences of heat transfer by forced convection. The Navier-stockes and energy equations have been solved numerically by the technique of CFD. Subsequently, the solutions were obtained using fluent code which uses the finite volume method. Han and Rank (1988) have developed a study on turbulent heat transfer in a rectangular channel with a sudden contraction at the entry. Hwang and Liou (1992) have studied the local characteristics of heat transfer with turbulent flow in a rectangular pipe with abrupt contraction at the entry. The natural turbulent convection along a vertical plate was experimentally examined by Mulawah (2002).

Because of their importance in industrial practice (heat exchanger, cooling of electronic components..), heat transfers by natural convection in cavities of complex geometries have been subject to numerous investigations.

For the complex dynamic behavior of the fluid at undulated walls level. Mahmud et al. (2002) have highlighted the effect of the undulating surface. Adjout et al. (2002) have studied the natural convection in an inclined, undulated cavity comprising an undulated hot wall. Prodip et al. (2003) have presented a numerical simulation of natural convection in an enclosure with undulated, plane vertically parallel walls. Saidi et al. (1987) have carried out a numerical and experimental study on the natural convection in a sinusoidal cavity. Mabrouk Rebhi et al. (2005) have presented a numerical simulation study of natural convection in a cavity with sinusoidal bottom.

To improve the functional performances of the heattransfer surface, this work concerns the study of the natural convection by laminar and turbulent flow in a vertical top- and bottom-open enclosure showing the role of protuberances. The horizontal walls are adiabatic.

\section{FORMULATION}

Adopting the Boussinesq approximation, the adimensional equations are written as:

\section{- Equations of Continuity}

$\frac{\partial U}{\partial X}+\frac{\partial V}{\partial Y}=0$

- Equations of Momentum

$\frac{\partial V}{\partial \tau}+U \frac{\partial V}{\partial X}+V \frac{\partial V}{\partial Y}=-\frac{\partial P}{\partial Y}+\frac{\partial^{2} V}{\partial X^{2}}+\frac{\partial^{2} V}{\partial Y^{2}}+G r^{*} \theta$

$\frac{\partial \mathrm{U}}{\partial \tau}+\mathrm{U} \frac{\partial \mathrm{U}}{\partial \mathrm{X}}+\mathrm{V} \frac{\partial \mathrm{U}}{\partial \mathrm{Y}}=-\frac{\partial \mathrm{P}}{\partial \mathrm{X}}+\frac{\partial^{2} \mathrm{U}}{\partial \mathrm{X}^{2}}+\frac{\partial^{2} \mathrm{U}}{\partial \mathrm{Y}^{2}}$

- Equations of Energy

$\frac{\partial \theta}{\partial \tau}+\mathrm{U} \frac{\partial \theta}{\partial \mathrm{X}}+\mathrm{V} \frac{\partial \theta}{\partial \mathrm{Y}}=\frac{1}{\operatorname{Pr}}\left(\frac{\partial^{2} \theta}{\partial \mathrm{X}^{2}}+\frac{\partial^{2} \theta}{\partial \mathrm{Y}^{2}}\right)$

The Nusselt local number $\mathrm{N}_{\mathrm{ux}}$ at the sinusoidal wall is calculated according to the relation below:

$\mathrm{N}_{\mathrm{ux}}=\frac{\mathrm{X}}{\theta_{\mathrm{p}}}\left(\frac{\partial \theta}{\partial \mathrm{N}}\right)$

Where, $\theta \mathrm{p}$ is the dimensionless temperature at the wall.

\subsection{Turbulence model}

Using the standard $k$ - $\varepsilon$ model for the turbulence coupling, the turbulence kinetic energy $k$ and its rate of dissipation $\varepsilon$ are obtained from the following transport equations:

$$
\begin{aligned}
\frac{\partial}{\partial t}(\rho k) & +\frac{\partial}{\partial x_{i}}\left(\rho k_{i}\right)= \\
& \frac{\partial}{\partial x_{j}}\left[\left(\mu+\frac{\mu_{t}}{\sigma_{k}}\right) \frac{\partial k}{\partial x_{j}}\right] \\
& +G_{k}+G_{b}-\rho \varepsilon-Y_{M}+S_{k}
\end{aligned}
$$

and

$$
\begin{aligned}
& \frac{\partial}{\partial t}(\rho \varepsilon)+\frac{\partial}{\partial x_{i}}\left(\rho \varepsilon_{u_{i}}\right)= \\
& \frac{\partial}{\partial x_{j}}\left[\left(\mu+\frac{\mu_{t}}{\sigma_{\varepsilon}}\right) \frac{\partial \varepsilon}{\partial x_{j}}\right]+C_{1 \varepsilon} \frac{\varepsilon}{k}\left(G_{k}\right. \\
& \left.+C_{3 \varepsilon} G_{b}\right)-C_{2 \varepsilon} \rho \frac{\varepsilon^{2}}{k}+S_{\varepsilon}
\end{aligned}
$$

$G_{k}$ represents the generation of turbulence kinetic energy due to the mean velocity gradients. $G_{b}$ is the generation of turbulence kinetic energy due to buoyancy. $Y_{M}$ represents the contribution of the fluctuating dilatation in compressible turbulence to the overall dissipation rate. $C_{1 \varepsilon}, C_{2 \vartheta}$ and $C_{3 \varepsilon}$ are constants. $\sigma_{k}$ and $\sigma_{\varepsilon}$ are the turbulent Prandtl numbers for $k$ and $\varepsilon$, respectively. $S_{k}$ and $S_{\varepsilon}$ are user-defined source terms.

\subsection{Modeling the Turbulent Viscosity}

The turbulent (or eddy) viscosity , $\mu_{t}$, is computed by combining $k$ and $\varepsilon$ as follows

$$
\mu_{t}=\rho C_{\mu} \frac{k^{2}}{\varepsilon}
$$


Where, $\boldsymbol{C}_{\boldsymbol{\mu}}$ is a constant.

The model constants $C_{1 \varepsilon}, C_{2 \curvearrowright} C_{\mu}, \sigma_{\mathrm{k}}$ and $\sigma_{\varepsilon}$ have the following default values:

$C_{1 \varepsilon}=1.44, C_{2 \varepsilon}=1.92, C_{\mu}=0.09, \sigma_{k}=1.0, \sigma_{\varepsilon}=1.3$

These default values have been determined from experiments with air and water for fundamental turbulent shear flows including homogeneous shear flows and decaying isotropic grid turbulence.

They have been found to work fairly well for a wide range of wall-bounded and free shear flows.

\section{MODEL GEOMETRY}

The physical system, considered in this work, consists of a vertical enclosure presenting in one of their vertical walls sinusoidal protuberances and openings at the bottom and the top of the vertical walls allowing the fluid flow. The horizontal walls are supposed adiabatic. This enclosure has a length $L$, a height $H$ and a width $L$, filled with a fluid (air), Fig.1. The width $L$ (in the direction perpendicular to the cross-section of the cavity) being selected is sufficiently large compared to the length $L$ so that the flow is two-dimensional.

\section{Numerical RESOlUtion}

The two-dimensional governing equations are solved by a CFD software which is primarily based on the method of finite volumes and is realized using the simpler logarithm. The choice of the meshing grid is selected in such a way that the refinement of the grid is of a high degree of accuracy in vertical sides precisely at the protuberances region.

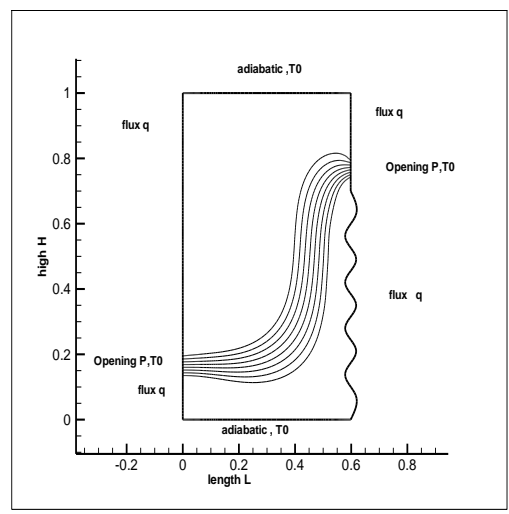

Fig. 1. Calculation Field with the imposed conditions (Contours represent the flow circulation).

\section{VALIDATION}

The results of the present numerical simulation code were validated by considering a cavity with protuberances on one of its walls. They have been compared to those of Khanafer et al. (2009) studying natural convection in an enclosure presenting protuberances in one of its vertical walls.

Figure 2 shows the streamlines for an amplitude of $a=0$ and $\mathrm{Ra}=10^{6}$. The present results are (a) and Khanafer's results are (b).

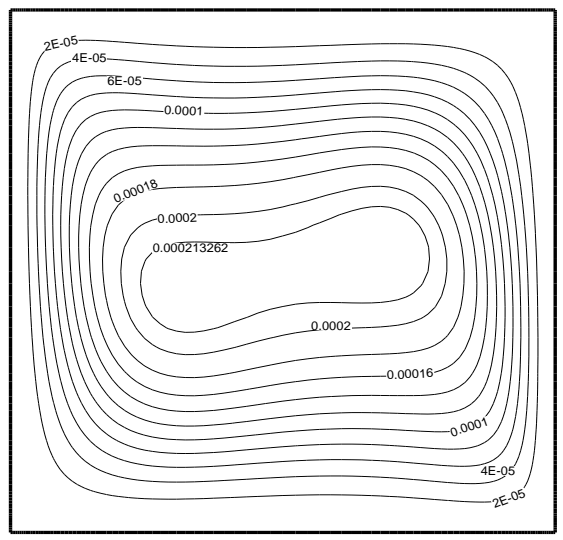

(a)

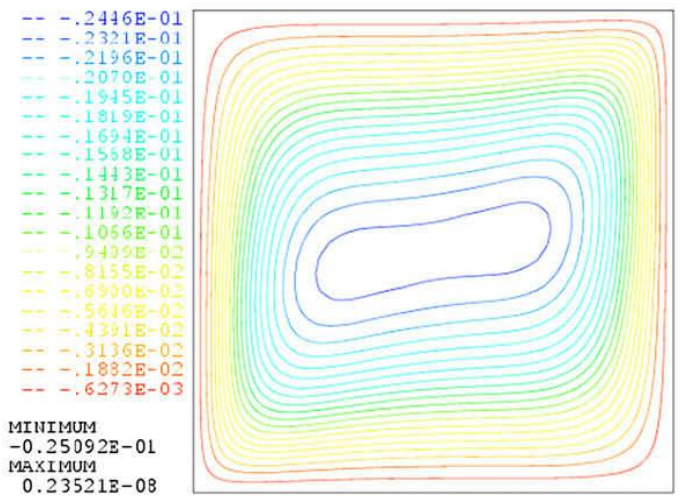

(b)

Fig. 2. Streamlines $\left(a=0, R a=10^{6}\right)$ for: (a) our calculation and (b) Khanafer et al. (2009)

Figures 3-5 give the results concerning an amplitude of $\mathrm{a}=0.025 \mathrm{~m}$ for the same Rayleigh number. With these parameters, our calculations were similar to those of Khanafer (streamlines in Fig. 3 and isotherms contour in Fig. 4 and Fig. 5.

In Fig. 6 we have plotted axial velocities evolution for our case and for Khanafer's. The present results are in a good agreement with the works of Khenafar et al. (2009). 
K. Rahmani et al. / JAFM, Vol. 6, No. 4, pp. 491-499, 2013.

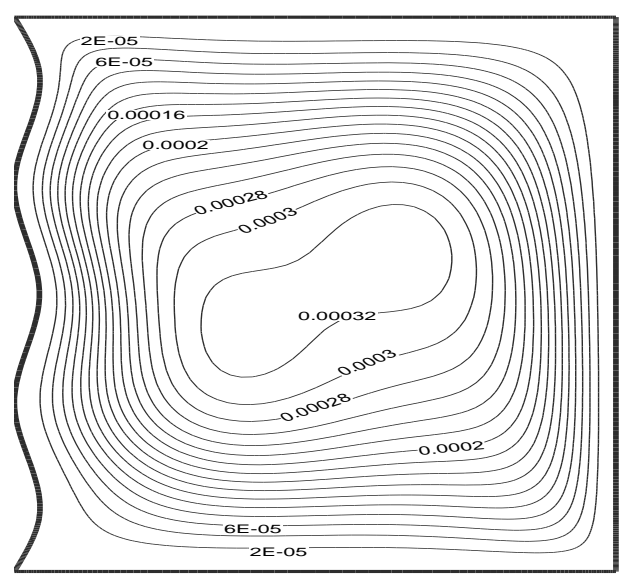

(a)

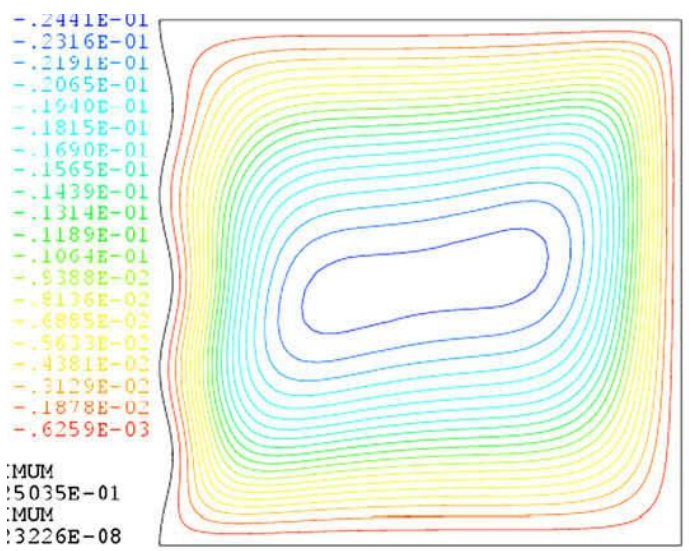

(b)

Fig. 3. Streamlines $\left(a=0.025 \mathrm{~m}, \mathrm{Ra}=10^{6}\right.$ ) for: (a) our calculation and (b) Khanafer et al. (2009)

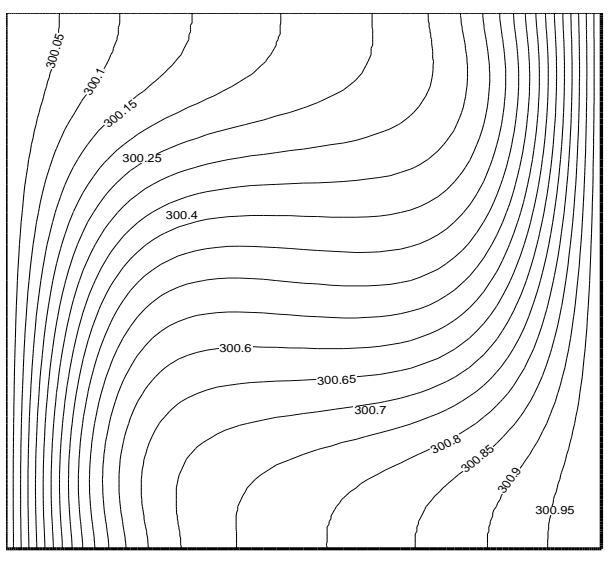

(a)

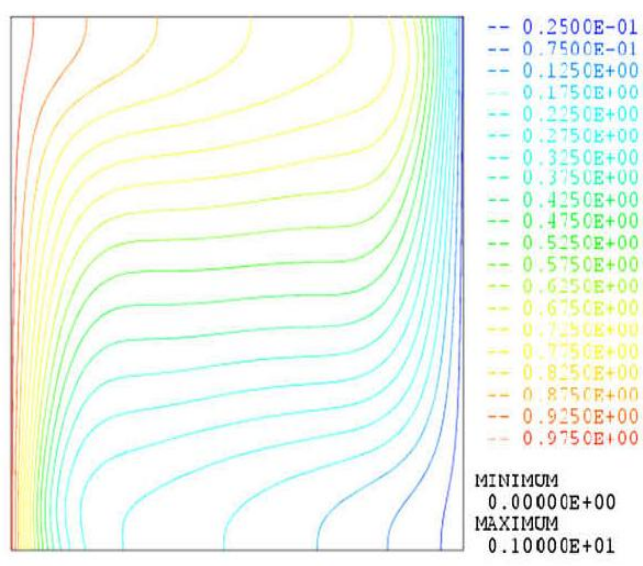

(b)

Fig. 4. Isotherm lines $(\mathrm{a}=0, \mathrm{Ra}=106)$ for: (a) our calculation and (b) Khanafer et al. (2009).

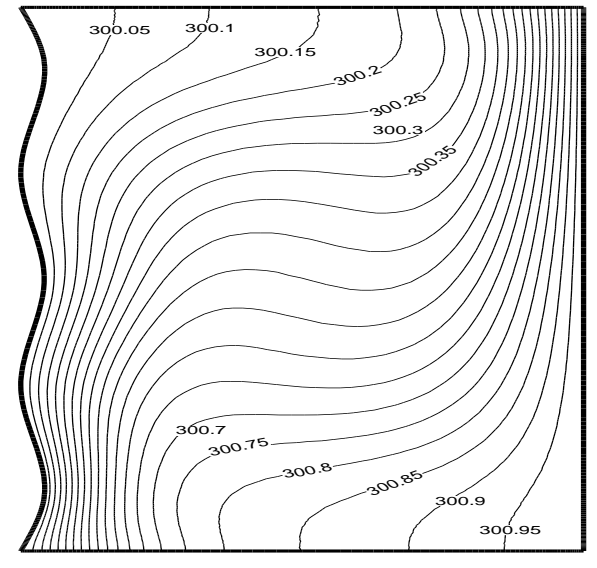

(a)
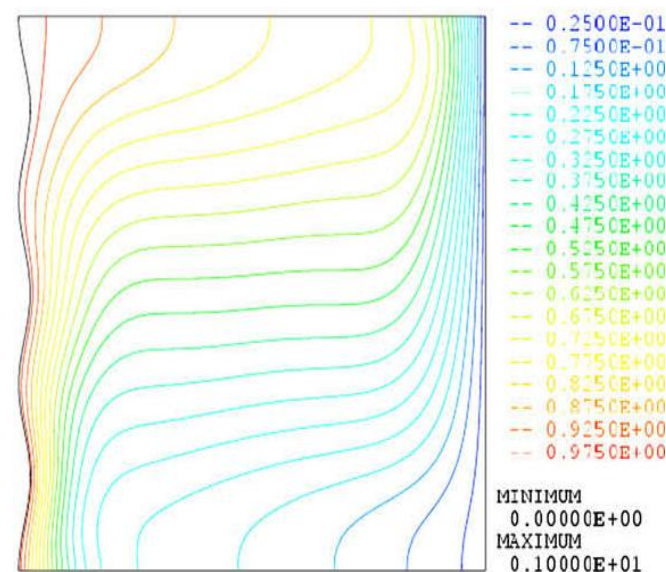

(b)

Fig. 5. Isotherm lines $(\mathrm{a}=0.025, \mathrm{Ra}=106)$ for :(a)Our calculation and (b) Khanafer et al. (2009) 


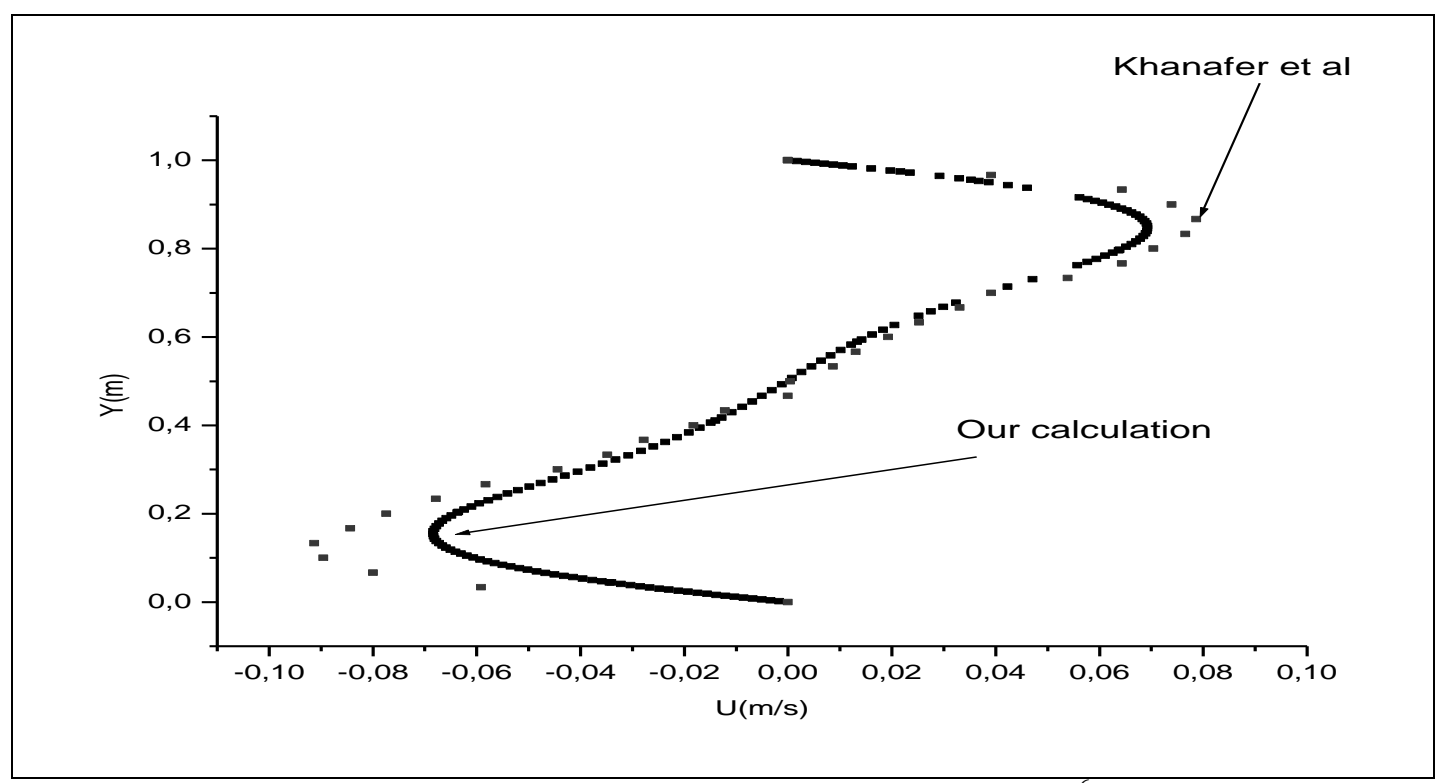

Fig. 6. Axial velocities profiles for $\mathrm{a}=0.025 \mathrm{~m}$ and $\mathrm{Ra}=10^{6}$

\section{RESUlTS AND DISCUSSION}

We have carried out a numerical study for various amplitudes. The results show various Factors like: temperature, local Nusselt number, turbulent kinetic energy $k$ and its dissipation $\varepsilon$.

Figures 7-10 show the fluid (air) flow characterized by the streamlines moving upward and by a set of contrarotating cells which meet in the hollows and at the tops of the sinusoid. We observe also, that the increasing of the amplitude, we have the formation of the vortices zone in the top and bottom regions of the cavity.

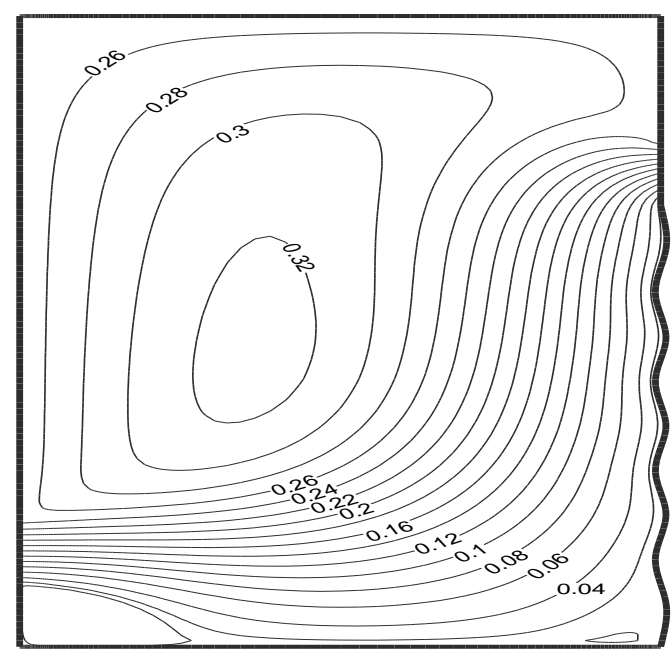

Fig. 7. Streamlines in the protuberant enclosure for an amplitude $\mathrm{a}=0.005 \mathrm{~m}$

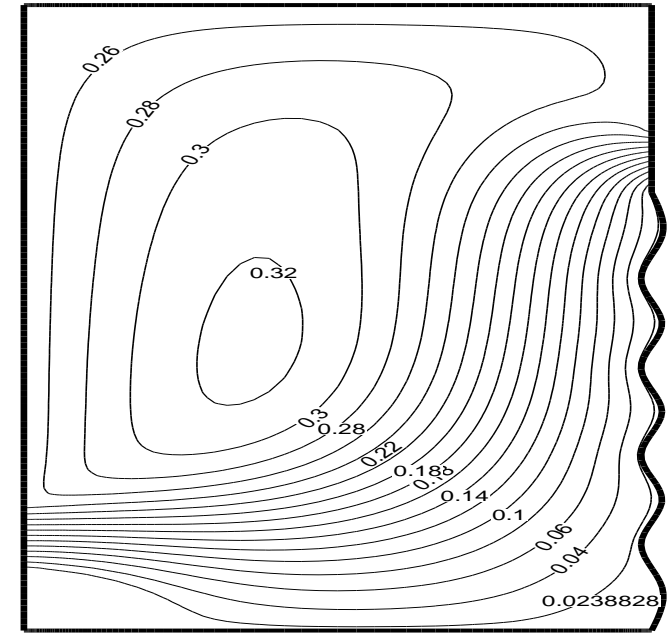

Fig. 8. Streamlines in the protuberant enclosure for an amplitude $\mathrm{a}=0.01 \mathrm{~m}$

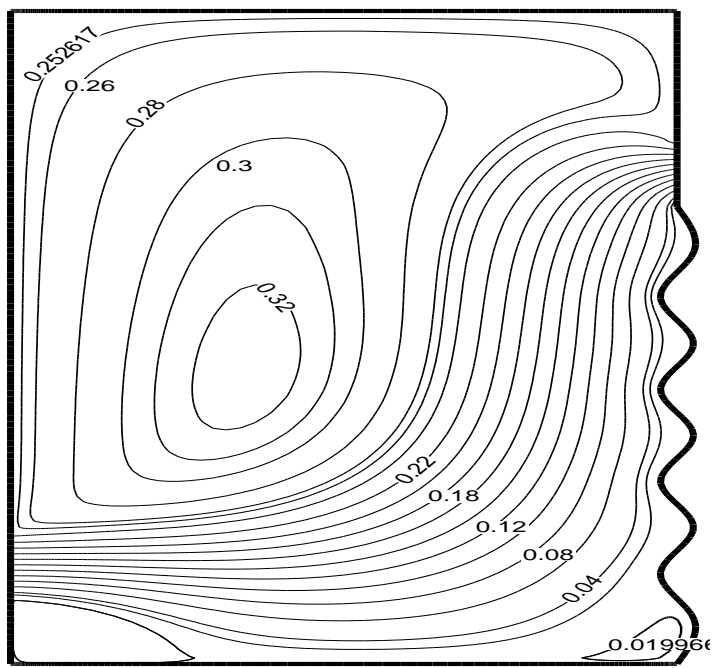

Fig. 9. Streamlines in the protuberant enclosure for an amplitude $\mathrm{a}=0.015 \mathrm{~m}$ 


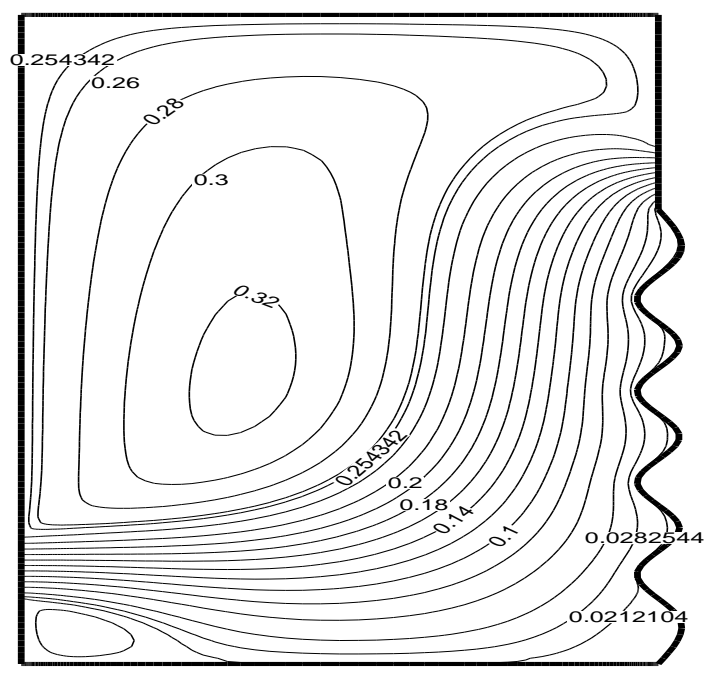

Fig. 10. Streamlines in the protuberant enclosure for an amplitude $\mathrm{a}=0.020 \mathrm{~m}$
Figure 11 presents the evolution of temperature profiles for various amplitudes. It is noticed that there is a progressive increase in temperature going from the low amplitude up to the high amplitude. This is due to the increase of the heat transfer surface in the deformed wall because the transfer in the sinusoids is carried out primarily by the mode of pure conduction and the natural convection transfer increases beyond the tops of the sinusoids.

In Fig.12 and Fig.13 respectively we observe the evolution of the Nusselt numbers and the turbulent kinetic energy according to the height of protuberance for various amplitudes. The effect of increasing the amplitudes generates a slight increase in turbulence as well as in the rate of heat transfer.

According to the same calculation, Fig.14 presents the evolution of temperature for various periods. We observe that temperature increases as protuberance periods increase for fixed amplitude according to the increase of the exchange area.

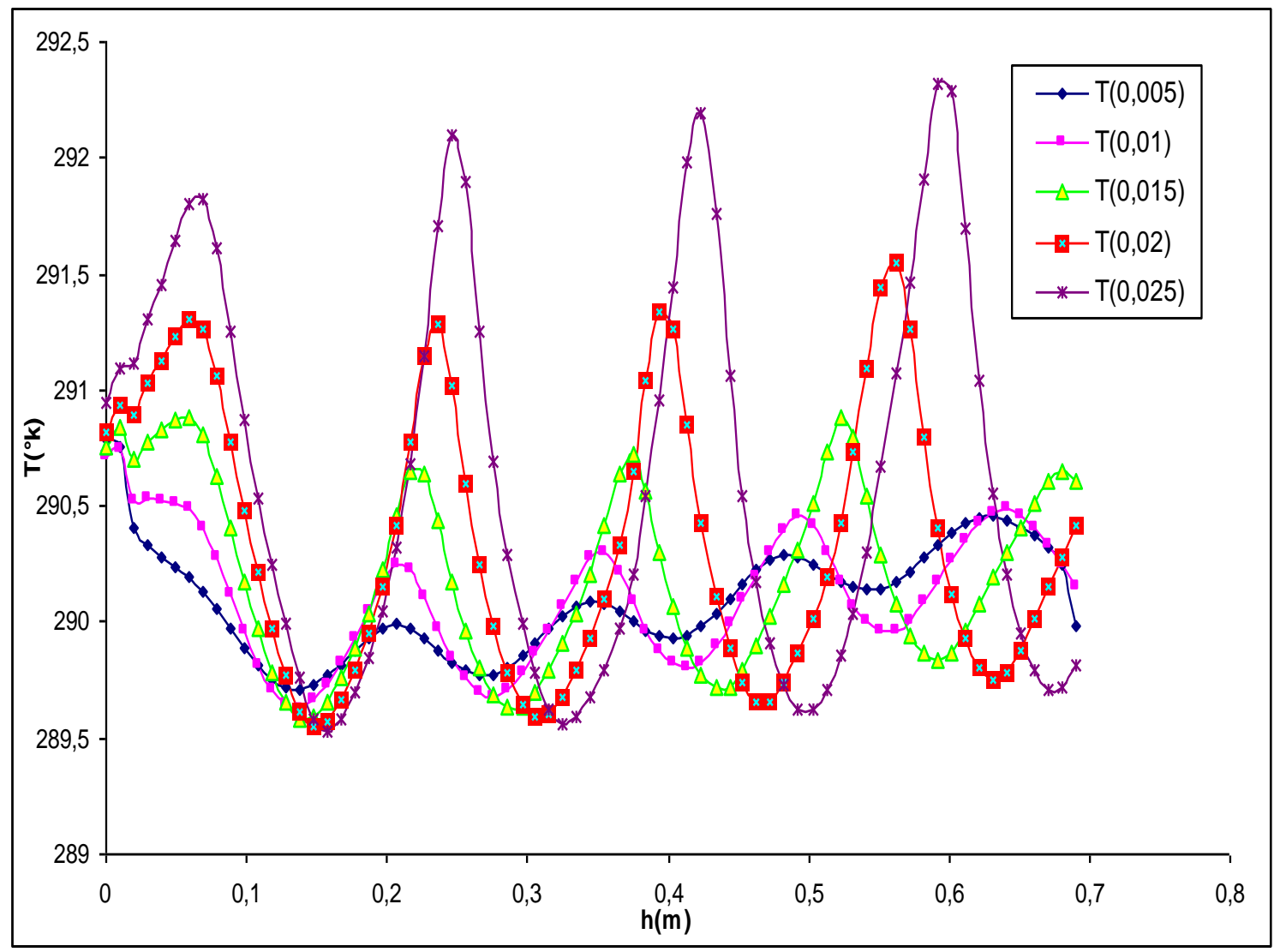

Fig. 11. Temperature profiles according to the height of the deformed wall, for various amplitudes 


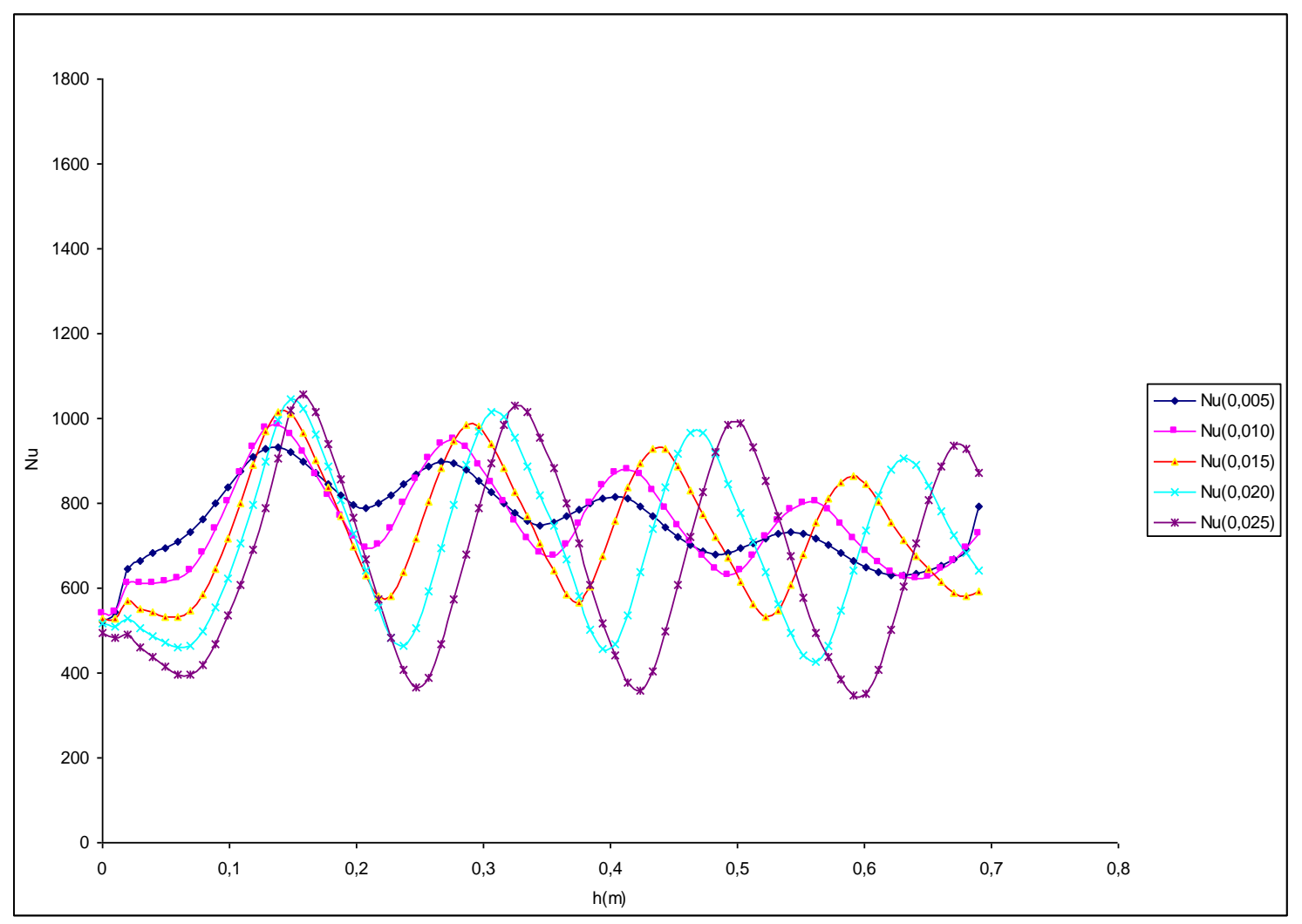

Fig. 12. Evolutions of Nusselt according to the height of the deformed wall, for various amplitudes

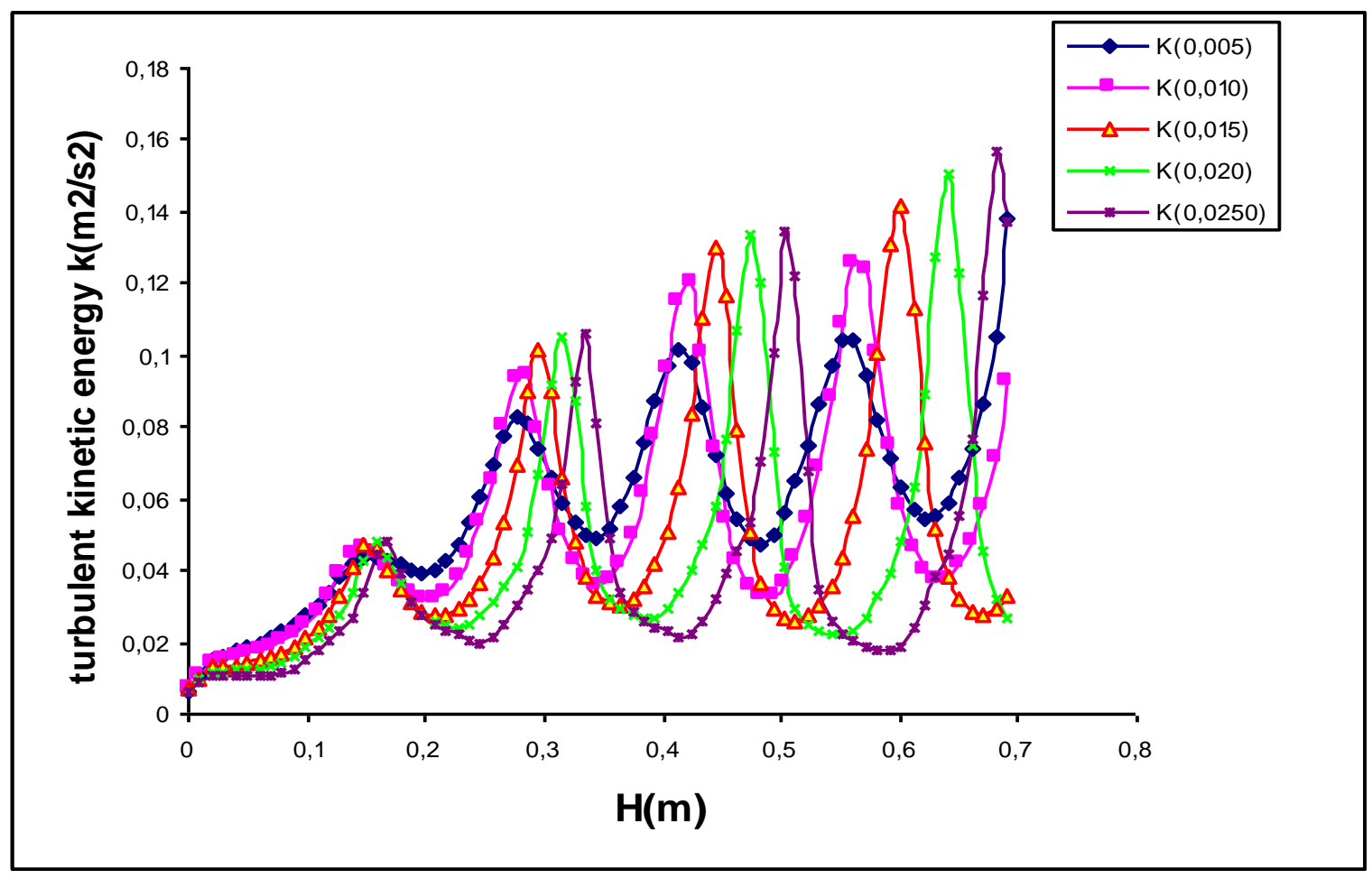

Fig. 13. Evolution of the turbulent kinetic energies versus the height of the protuberances, for various amplitudes 


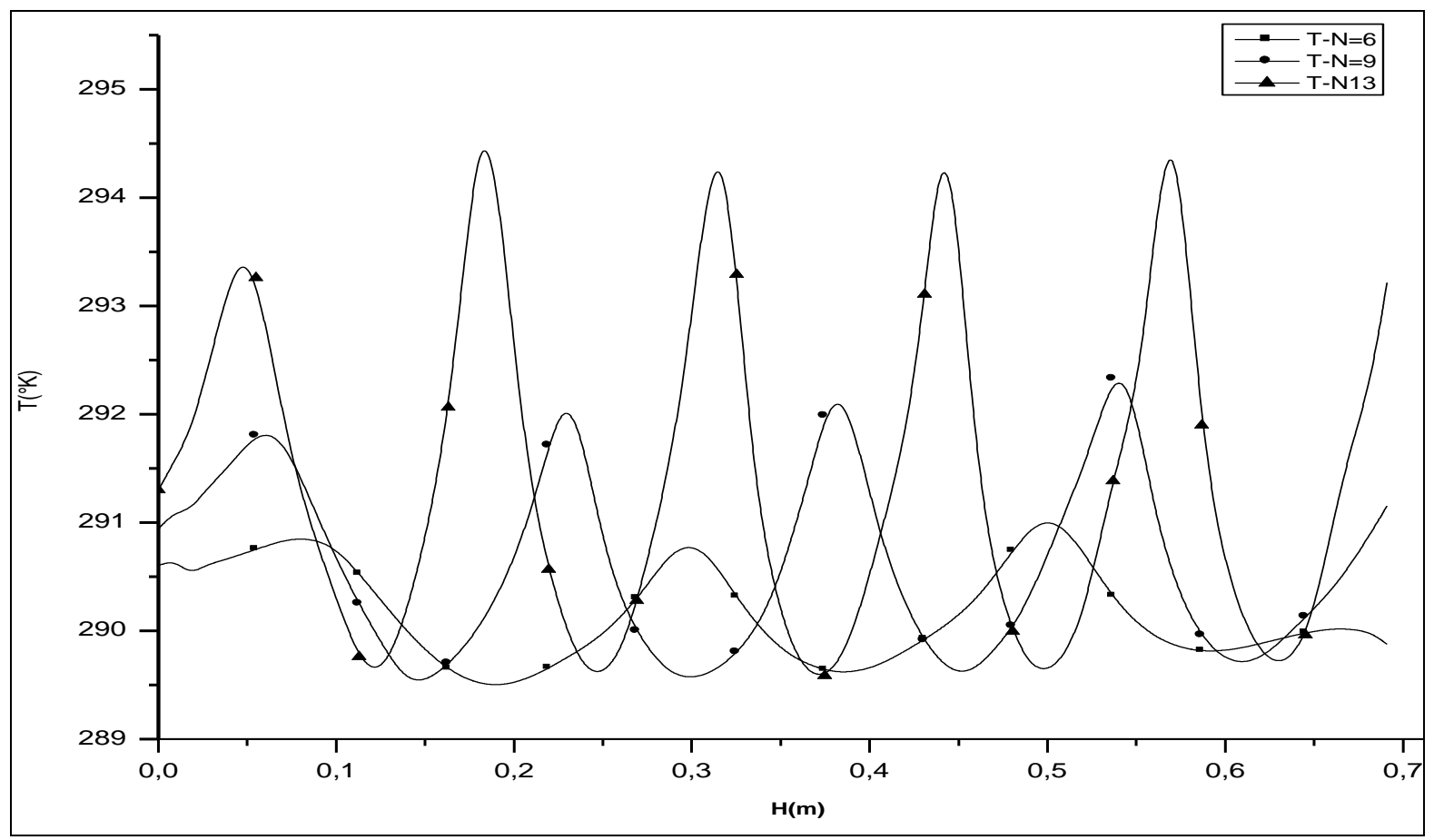

Fig. 14. Evolution of the Temperature versus the height of the protuberances, for various periods

\section{ConClusion}

In this work, we studied the influence of three factors evolution, in an enclosure presenting the vertical walls which is partially deformed. Two openings on the vertical walls are posed; the obtained results show that the flow is characterized by a circulation upwards and undulatory in the vicinity of the protuberances (hollow). In the vicinity of the sinusoids, we note the existence of a mode of heat transfer, purely, conductive and beyond the tops there which will be the convective mode where the numbers of Nusselt are higher compared with a heat transfer for a plane wall.

According to these results of this work, we can conclude that our calculation seems in concordance with some other works found in literature for simple geometries. In our case, the study represents a coupling of protuberances and opening in the same cavity.

\section{REFERENCES}

Adjlout, L., O. Imine, A. Azzi, and M. Belkadi (2002). Laminar natural convection in an inclined cavity with a wavy wall, Int. J. of Heat and Mass Transfer, 45, 2141-2152.

Aounallah, M., Y. Addad, S. Benhamadouche, O. Imine, L. Adjlout, and D. Laurence (2007). Numerical investigation of turbulent natural convection in an inclined square cavity with a hot wavy wall. Int. J. Heat Mass Transfer, 50,16831693.

Bairi, A., N.Laraqi, and G.de Maria. (2007). Numerical and experimental study of natural convection in tilted parellelepipedic cavities for large Rayleigh numbers. Exp. Therm. Fluid Sci., 31, 309-324.

Behnia, M., J. Rizes, and G .De Vahl Davis (1990). Combined radiation and natural convection in a cavity with a transparent wall and containing a nonparticipant fluid. Int. J. Numer. Meth. Fluids, 10, 305-325.

Bejan, A. (1995). Convective Heat Transfer, second ed. Wiley, New York. Brinkman, H.C., 1952. The viscosity of concentrated suspensions and solutions. J. Chem. Phys., 20,571-581.

Catton, I. (1978). Natural convection in enclosures. In: Proceedings of the Sixth International Heat Transfer Conference, 6.

Chowdhury, S. and J. Ahmadi (1992). A thermodynamically consistent rate-dependent model for turbulence. Part II. Computational results, Int. J. Non-linear Mechanics, 27, 705-718.

De Vahl Davis, G. and I.P. Jones (1983). Natural convection in a square cavity: a benchmark numerical solution. Int. J. Numer. Meth. Fluid, 3, 227-248.

Elsherbiny, S.M. (1996). Free convection in inclined air layers heated from above. Int.J. Heat Mass Transfer, 39, 3925-3930.

Han J.C. and Park (1988), Developing heat transfer in rectangular channels with rib tabulators, Int. J. Heat Mass Transfer, 31, 183-195. 
K. Rahmani et al. / JAFM, Vol. 6, No. 4, pp. 491-499, 2013.

Hwang, L. and J.Liou (1992). Developing heat transfer and friction in a ribbed rectangular duct with flow separation at inlet, ASME J. Heat Transfer, 114,554573.

Khalifa Abdul-Jabbar, N. (2001). Natural convective heat transfer coefficient - a review, II. Isolated vertical and horizontal surfaces. Energy Convers. Manage, 42, 505-517.

Khanafer, K., B. Al-Azmi, A. Marafie, and L. Pop (2009) . Non-Darcian effects on natural convection heat transfer in a wavy porous enclosure. International Journal of Heat and Mass Transfer, 52, 1887-1897.

Larson, D. and R. Viskanta (1976). Transient combined laminar free convection and radiation in a rectangular enclosure. J. Fluid Mech., 78, 65-85.

Mahmud, S., P. K. Das, N. Hyder, and I. AKMS (2002). Free convection heat transfer in an enclosure with vertical wavy walls. International Journal of Thermal Sciences, 41, 440-446.

Mulaweh, H.I.A. (2002). Effects of backward- and forward-facing steps on turbulent natural convection flow along a vertical flat plate, Int. J. Thermal Sci., 41, 376-385.
Ostrach, S. (1988). Natural convection in enclosures. $J$. Heat Transfer, 110, 1175-1190.

Prodip, D. and M. Shohel (2003). Numerical investigation of natural convection inside a wavy enclosure, Int. J. of Thermal Sciences, 42, 397-406.

Rebhi, M., B. Abdellah, and A. Touhami (2005). Simulation numérique de la convection naturelle dans une cavité à fond sinusoïdal, 12èmes Journées Internationales de Thermique Tanger, Maroc.

Saidi, C., F. Legaye, and B. Pruent (1987). Laminar low past a sinusoidal cavity, Internat. J. Heat Mass Transfer, 30, 649-660.

Webb, B. and R. Viskanta (1987). Radiation-induced buoyancy-driven flow in rectangular enclosures: experiment and analysis. J. Heat Transfer, 109, 427433.

Yilmaz, I. and H. F. Oztop (2006). Turbulence forced convection heat transfer over double forward facing step flow, Int. Comm. Heat Mass Transfer, 33, 508517. 